\title{
Effects of Solution Atoms and Precipitates on Isochronal Annealing Behavior of Cold-Rolled Squeeze-Cast SiCw/Al Composites
}

\author{
Wenglong Zhang, Mingyuan Gu \\ State Key Lab of MMCs, Shanghai Jiao Tong University, Shanghai, China. \\ Email: zhangwl@sjtu.edu.cn \\ Received October $4^{\text {th }}, 2010$; revised December $16^{\text {th }}, 2010$; accepted May $11^{\text {th }}, 2011$.
}

\begin{abstract}
$\mathrm{SiCw} / \mathrm{Al}$ and SiCw/6061Al composites, which contained $15 \mathrm{vol}$ pct of whiskers, were fabricated through a squeeze cast route followed by cold rolling and isochronal annealing. Effects of whicker, solution atoms and precipitates on isochronal annealing behavior of cold rolled composites were investigated by comparing the isochronal annealing behavior between pure Al, SiCw/Al, solution-treated $\mathrm{SiCw} / 6061 \mathrm{Al}$ and aged $\mathrm{SiCw} / 6061 \mathrm{Al}$. It was found that the recrystallization of SiCw/Al composite occurs earlier than that of pure Al, indicating SiCw has a role of particle stimulated nucleation. Solution atoms have no significant influence on the isochronal annealing behavior of SiCw/6061Al composite, while precipitates have such a strong retarding effect on the recrystallization of SiCw/6061Al composite that the isochronal annealing curve of aged SiCw/6061 composite loses the definable recrystallization step.
\end{abstract}

Keywords: Composite Materials, Deformation and Fracture, Isochronal Annealing, Precipitates

\section{Introduction}

Aluminum metal matrix composites (AMCs) are now recognized as candidate materials for aerospace and automotive industries because of their low density, high stiffness and strength. AMCs containing discontinuous reinforcement, such as particulate, whisker or short fiber, are especially attractive because they can be readily shaped with conventional secondary metal-working techniques [1-10]. During such forming operations, AMCs may experience an appreciable amount of cold working, which may both influence their further forming operations and degrade mechanical properties, such as elongation to failure and fatigue resistance. Therefore, after forming operations it may be necessary to anneal the composites to recover their deformation ability and mechanical properties [7,11-18]. To optimize forming operations and mechanical properties of AMCs, understanding the annealing behavior of plastically deformed AMCs is essential.

Recent studies $[8,12-20]$ have examined the microstructural development in AMCs during annealing operations. These studies focus mostly on AMCs manufactured by powder metallurgy route, including particulate- and whisker-reinforced composites, in which fine dispersions of $\mathrm{Al}_{2} \mathrm{O}_{3}$ is present. It was reported that, for powder metallurgy $\mathrm{Al}-\mathrm{SiCw}$ composites, the reinforcing whiskers were of a significant influence on the deformation and recrystallization behavior of the matrix alloy [11-14]. Firstly, when whisker volume fraction was equal to or less than $8 \%$, the presence of whiskers resulted in a more inhomogeneous deformed microstructure in the matrix of AMCs compared with those unreinforced materials. And the recrystallization rate of AMCs was usually faster than that of the corresponding unreinforced alloy in this case. When whisker volume fraction was equal to $10 \%$, the presence of whiskers led to a delocalized structure with many highly misorientated equiaxed subgrains, and recrystallization as a result of nucleation and growth didn't occur. Secondly, the fine dispersions of $\mathrm{Al}_{2} \mathrm{O}_{3}$ reduced recovery reaction and also inhibited the recrystallization. For the powder metallurgy Al-SiCp composites [4], it was found that recrystallization resulted in an obvious hardness drop for Al-18vol. pct SiCp composite, but not for Al-35vol pct SiCp composite. It was not clear whether or not recrystallization had occurred in the Al- $35 \mathrm{vol}$ pct $\mathrm{SiCp}$ composite [4]. Squeeze cast $\mathrm{SiCw} / \mathrm{Al}$ com- posites are different in microstructure from the powder 
metallurgy ones. One of the main differences is that squeeze cast $\mathrm{SiCw} / \mathrm{Al}$ composites contain no fine dispersions of $\mathrm{Al}_{2} \mathrm{O}_{3}$. This may lead to an annealing behavior in squeeze cast composites which is different from that in powder metallurgy ones. The reason why powder metallurgy composites of Al-10vol. pct $\mathrm{SiCw}$ didn't show recrystallization behavior may be due in part to the role of fine dispersions of $\mathrm{Al}_{2} \mathrm{O}_{3}$. In order to both eliminate effects of solution atoms and precipitates existing in matrix and make a direct comparison between reinforced and unreinforced materials, research on recrystallization has been carried out on a range of MMCs with commercially pure aluminum as the matrix $[11,13,14]$. However, MMCs with pure aluminum as matrix are rarely used in engineering applications; therefore it is necessary to investigate the recrystallization of MMCs with aluminum alloys as matrix from the point of view of engineering applications. Because the existence of alloying elements, the annealing behavior of the composites with aluminum alloys as matrix may be much different from that of the composites with pure aluminum as matrix.

In this study, two composites (squeeze cast $\mathrm{SiCw} / \mathrm{Al}$ and $\mathrm{SiCw} / 6061 \mathrm{Al}$ composites), which contained 15 vol. pct of whiskers, was cold rolled and annealed. Effects of solution atoms and precipitates on isochronal annealing behavior of the cold rolled composite were investigated.

\section{Materials and Methods}

The composites used in this study were reinforced with $\beta$ type $\mathrm{SiC}$ whiskers, $0.1-1.0 \mu \mathrm{m}$ in diameter and $30-100$ $\mu \mathrm{m}$ in length. The matrix is commercially pure aluminum ( $\geq 99.5 \mathrm{wt}$ pct $\mathrm{Al}$ ) or 6061 alloy. The composites were fabricated through a squeeze-cast route and had a $\mathrm{SiC}$ whisker volume fraction, $V_{f}$, of $15 \%$. It was difficult to cold deform the as-cast composites due to its bad ductility. To obtain a higher cold deformation degree, the as-cast composites were subjected to a hot extrusion with an extrusion ratio of 18:1 before cold rolling. It was found that the capability of cold deformation of $\mathrm{SiCw} / \mathrm{Al}$ composites could be greatly improved by the pre-hotextrusion. The as-extruded composites were then coldrolled along the extrusion direction to about 30 pct reduction in thickness. The spatial distribution of $\mathrm{SiC}$ whiskers in cold-rolled sheets was fairly uniform and highly aligned along the rolling direction i.e. the extrusion direction, as shown in Figure 1. For $\mathrm{SiCw} / 6061 \mathrm{Al}$ composites, solution treatment was carried out at $520^{\circ} \mathrm{C}$ and water quenched. Then some of the solution-treated composites were aged at $170^{\circ} \mathrm{C}$ for $10 \mathrm{~h}$. Isochronal annealing was performed for $1 \mathrm{~h}$ in a temperature range from 100 to $500^{\circ} \mathrm{C}$. Vickers macrohardness measurement

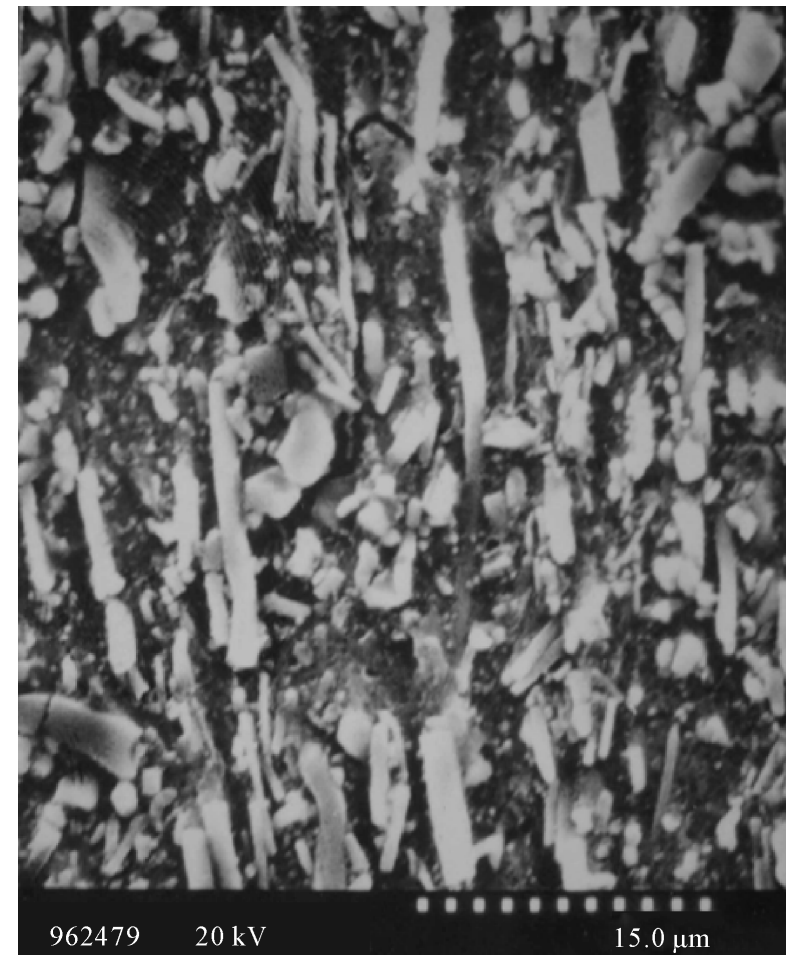

Figure 1. Whisker morphology in cold rolled SiCw/Al composites. The reduction in thickness is $30 \%$.

was carried out using $5 \mathrm{~kg}$ load on the cold-rolled and annealed specimens. On an average, ten hardness measurements were performed on each specimen for each date point. Microstructures of the cold-rolled and aged samples were studied by scanning electron microscopy (SEM) and transmission electron microscopy (TEM).

\section{Results and Discussion}

Figure 2 shows the isochronal annealing curves of the cold rolled composites and pure Al. It can be seen from the figure that, for all the materials, hardness decreases with the increase in annealing temperature. For solution-treated $\mathrm{SiCw} / 6061 \mathrm{Al}, \mathrm{SiCw} / \mathrm{Al}$ and $\mathrm{Al}$, the isochronal annealing curves are similar in shape and show definable transition steps from the higher to the low hardness values. For aged $\mathrm{SiCw} / 6061$, however, the isochronal annealing curve is nearly linear in shape and without a definable recrystallization step. Comparing the isochronal annealing curve of pure $\mathrm{Al}$ with that of its composite $(\mathrm{SiCw} / \mathrm{Al})$, it is found that the starting recrystallization temperature of $\mathrm{SiCw} / \mathrm{Al}$ (about $200^{\circ} \mathrm{C}$ ) is lower than that of pure $\mathrm{Al}$ (about $240^{\circ} \mathrm{C}$ ), indicating that $\mathrm{SiCw}$ may play a big role in stimulating recrystallization nucleation. The similar isochronal annealing curve shape between solution-treated $\mathrm{SiCw} / 6061 \mathrm{Al}$ and $\mathrm{SiCw} / \mathrm{Al}$ suggests that the isochronal recrystallization behaviour of 


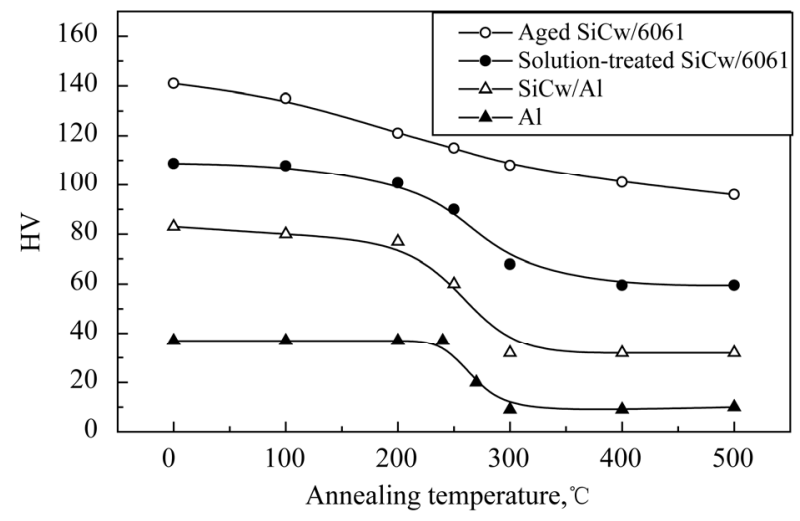

Figure 2. Isochronal annealing curves for cold rolled SiCw/ Al composites and pure Al. The reduction in thickness is $30 \%$.

solution-treated $\mathrm{SiCw} / 6061 \mathrm{Al}$ may be similar to that of $\mathrm{SiCw} / \mathrm{Al}$. Because the only difference between solution-treated $\mathrm{SiCw} / 6061 \mathrm{Al}$ and $\mathrm{SiCw} / \mathrm{Al}$ is that there are solute atoms in the matrix in the former but not in the latter, it can be said that solute atoms in solution have no significant influence on isochronal annealing behaviour of $\mathrm{SiCw} / \mathrm{Al}$. That is to say, putting the solute atoms into the $\mathrm{SiCw} / \mathrm{Al}$ and making them in solution would not significantly change the isochronal recrystallization behavior of $\mathrm{SiCw} / \mathrm{Al}$. The hardness drops of the composites causing by annealing are shown in Figure 3. It can be clearly seen that the hardness drop of aged $\mathrm{SiCw} / 6061 \mathrm{Al}$ is much less than those of $\mathrm{SiCw} / \mathrm{Al}$ and solution-treated $\mathrm{SiCw} / 6061$.

The differences in isochronal annealing behavior between pure $\mathrm{Al}, \mathrm{SiCw} / \mathrm{Al}$ and aged $\mathrm{SiCw} / 6061 \mathrm{Al}$ can be explained from the viewpoint of particle size. Figure 4 shows precipitates in aged $\mathrm{SiCw} / 6061 \mathrm{Al}$. It can be seen that the round precipitates exist in the aged $\mathrm{SiCw} / 6061 \mathrm{Al}$. The average radius and volume fraction of the precipitates were measured to be about $0.05 \mu \mathrm{m}$ and $3 \%$. It is well known that the kinetics of recrystallization is strongly affected by a dispersion of particles. Generally, fine and closely spaced particles inhibit recrystallization, whereas large and widely spaced particles promote recrystallization $[21,22]$. The transition between accelerated and retarded recrystallization is primarily dependent on the dispersion parameter and typically occurs at a value of $f / r \sim 0.2$ to $0.4 \mu^{-1}$ [22] where $f$ is the volume fraction and $r$ is the particle radius. In the present materials, $\mathrm{SiCw}$ has $f / r$ value of $\sim 0.34 \mu \mathrm{m}^{-1}$ ( $f$ is $15 \%$ and $r$ is about $0.44 \mu \mathrm{m}$ ) and hence should accelerate the recrystallization. However, the precipitates have $f / r$ value of $\sim 0.6$ ( $f$ is $3 \%$ and $r$ is about $0.05 \mu \mathrm{m}$ ) which is more than 0.5 and hence should retard the recrystallization. In the case there is only $\mathrm{SiCw}$, such as in $\mathrm{SiCw} / \mathrm{Al}$, the recrys-

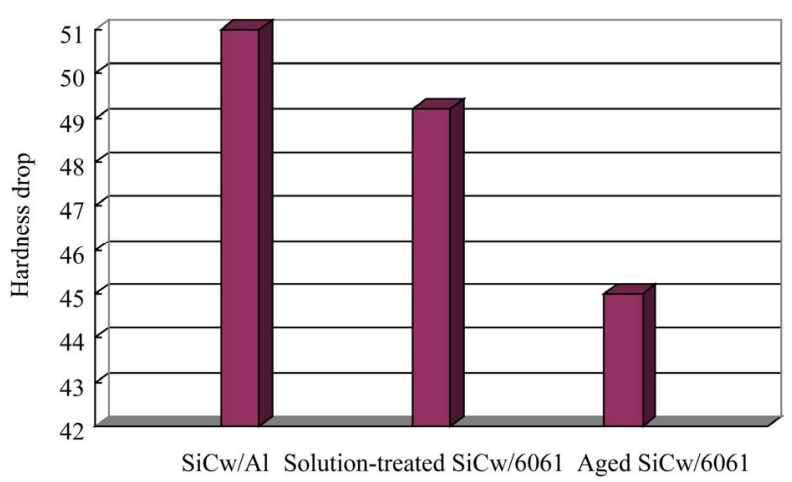

Figure 3. Hardness drop before and after annealing.

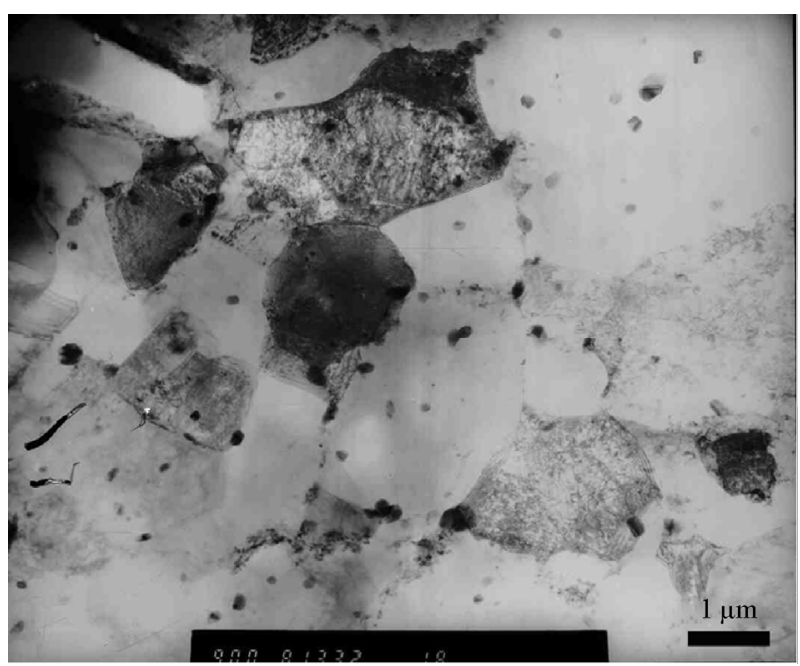

Figure 4. Precipitates in the matrix of aged $\mathrm{SiCw} / 6061$ composite.

tallization is accelerated, and hence $\mathrm{SiCw} / \mathrm{Al}$ has a lower starting recrystallization temperature compared with the pure Al (Figure 2). In the case of aged SiCw/6061Al, however, in addition to $\mathrm{SiCw}$ there are precipitates. The two types of particles (whiskers and precipitates) will have an opposing effect on the recrystallization process, and hence resulting in the isochronal annealing curve without a definable recrystallization step.

\section{Conclusions}

1) The existence of $\mathrm{SiCw}$ can stimulate recrystallization nucleation of $\mathrm{SiCw} / \mathrm{Al}$ composite;

2) Solution atoms have no significant influence on the isochronal annealing behavior of $\mathrm{SiCw} / 6061 \mathrm{Al}$ composite;

Precipitates retard recrystallization of $\mathrm{SiCw} / 6061 \mathrm{Al}$ composite so strongly that the isochronal annealing curve of aged $\mathrm{SiCw} / 6061$ composite loses the definable recrystallization step. 


\section{REFERENCES}

[1] K. Suganuma and T. Fujita, "Hot Extrusion of AA7178 Reinforced with Alumina Short Fibre," Materials Science and Technology, Vol. 5, No. 8, August 1989, pp. 249254.

[2] M. Lieblich and G. J. Gonzalez-Doncel, "Extrudability of PM 2124/SiC $\mathrm{p}$ Aluminium Matrix Composite," Materials Letters, Vol. 16, No. 1, January 1997, pp. 726-728.

[3] W. Zhang and D. Wang, "Forming Process of Hot-Extruded SiCw/6061Al Composites," Transactions of Nonferrous Metals Society of China, Vol. 8, No. 3, March 1998, pp. 432-436.

[4] F. J. Humphreys and W. S. Miller, "A Network Model for Recovery and Recrystallization," Materials Science and Technology, Vol. 6, No. 1, January 1990, pp. 1157-1166.

[5] R. D. Doherty, D. A. Hughes and F. J. Humphreys, "Current Issues in Recrystallisation: A Review," Materials Science and Engineering A, Vol. 238, No. 2, February 1997, pp. 219-274. doi:10.1016/S0921-5093(97)00424-3

[6] R. Nagarajan and I. Dutta, "A Novel Approach for Optimizing the Fracture Toughness of Precipitation-Hardenable Al-SiCp Composites," Metallurgical and Materials Transactions A, Vol. 32A, No. 2, February 2001, pp. 433-436. doi:10.1007/s11661-001-0276-6

[7] N. Yazdian, F. Karimzadeh and M. Tavoosi, "Microstructural Evolution of Nanostructure 7075 Aluminum Alloy during Isothermal Annealing," Journal of Alloy and Compounds, Vol. 493, No. 1-2, February 2010, pp. 137141. doi:10.1016/j.jallcom.2009.12.144

[8] W. B. Du, K. Tatsuzawa and T. Aizawa, "Forming and Microstructure Control of Ceramic/Metal Composite Wires," Materials Letters, Vol. 54, No. 2-3, May 2002, pp. 145-151. doi:10.1016/S0167-577X(01)00553-5

[9] B. Sustarsic, M. Dobersek and B. Breskvar, "Properties of Hot Extruded Al Sic Metal Matrix Composites," Metalurgija, Vol. 38, No. 3, July 1999, pp. 143-149.

[10] H. Xu and E. J. Palmiere, "Particulate Refinement and Redistribution during the Axisymmetric Compression of an $\mathrm{Al} / \mathrm{SiCp}$ Metal Matrix Composite," Composites A, Vol. 30, No. 3, March 1999, pp. 203-211. doi:10.1016/S1359-835X(98)00169-9

[11] Y. L. Liu and N. Hansen, "Recrystallisation Microstructure in Cold-Rolled Aluminium Composites Reinforced by Silicon Carbide Whiskers," Metallurgical and Materials Transactions A, Vol. 20A, No. 2, February 1989, pp. 1743-1753. doi:10.1007/BF02663206

[12] D. J. Jensen and N. Hansen, "Effect of Recrystallization
Temperature on Texture and Grain Size of Al-SiC Composites," Materials Science and Technology, Vol. 7, No. 9, September 1991, pp. 369-375.

[13] Y. L. Liu and D. J. Jensen, "Hardening Behaviour of Metal Matrix Composites Coupled to Numerical Predictions," Strength of Materials, Vol. 23A, No. 2, February 1994, pp. 381-384.

[14] Y. L. Liu and N. Hansen, "Effect of Dispersion Parameters and Cold Deformation on Recrystallization in of Al-SiC Composites," Materials Science and Technology. Vol. 7, No. 6, June 1991, pp. 270-275.

[15] D. Yu and P. R. Munroe, "Recrystallization in Sic Particulate-Reinforced 6061-Aluminum Metal-Matrix Composites Following Low Strain Deformation," Scripta Metallurgical and Materials, Vol. 30, No. 7, July 1994, pp. 927-932. doi:10.1016/0956-716X(94)90417-0

[16] R. Manna and J. J. Sarkar, "Effect of Second Phase Precipitation on Recovery and Recrystallization Behaviour of

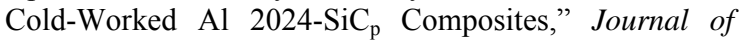
Materials Science, Vol. 31, No. 2, February 1996, pp. 1625-1631. doi:10.1007/BF00357874

[17] R. A. Shahani and T. W. Clyne, "Recrystallization in Fibrous and Particulate Metal Matrix Composites," Materials Science and Engineering A, Vol. 4, No. 2, February 1994, pp. 281-285.

[18] D. Yu and P. R. Munroe, "Microstructural Evolution of a Cold-Deformed 6061Al Reinforced with SiC Particles during Subsequent Annealing," Journal of Materials Science, Vol. 31, No. 3, February 1996, pp. 625-631. doi:10.1007/BF00367878

[19] J. M. Root, D. P. Field and T. W. Nelson, "Crystallographic Texture in the Friction-Stir-Welded Metal Matrix Composite Al6061 with 10 Vol Pct $\mathrm{Al}_{2} \mathrm{O}_{3}$," Metallurgical and Materials Transactions A, Vol. 40A, No. 9, September 2009, pp. 2109-2114. doi:10.1007/s11661-009-9883-4

[20] L. Ceschini, G. Minak and A. Morri, "Forging of the AA6061/23 vol $\% \mathrm{Al}_{2} \mathrm{O}_{3}$ p Composite: Effects on Microstructure and Tensile Properties," Materials Science and Engineering A, Vol. 513-514, No. 5, May 2009, pp. 176184. doi:10.1016/j.msea.2009.01.057

[21] F. J. Humphreys, "Recrystallization Mechanisms in TwoPhase Alloys," Materials Science, Vol. 13, No. 5, May 1979, pp. 136-145.

[22] P. Cotterill and P. R. Mould, "Recrystallization and Grain Growth in Metals," Surrey University Press, Guildford, 1976. 